\title{
BLDC Motor Speed Measurement Using ZCP Detection for Fuzzy Speed Controlling
}

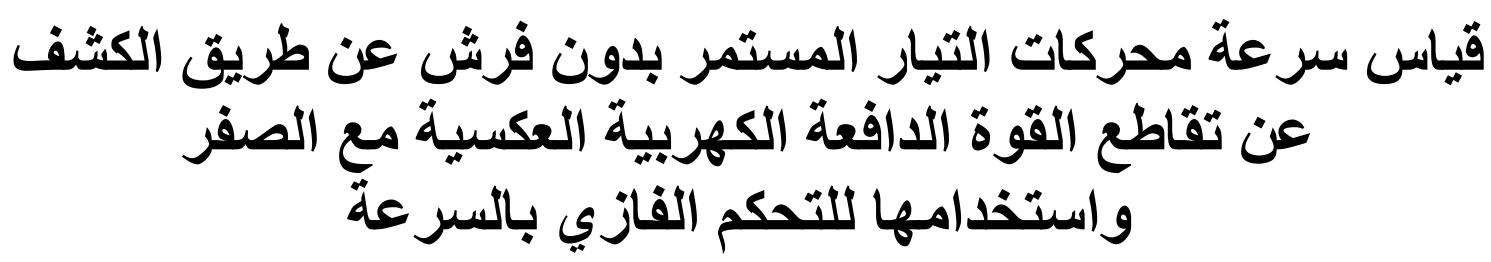

\section{Mohamed S. Elksasy $^{(1)}$, Ahmed M. Ahmed ${ }^{(2)}$, Amr Ali-Eldin ${ }^{(3)}$ \& Faiz F. Areed $^{(4)}$}

(1) Assist. Prof. at Computers and Systems Engineering Department, Faculty of Engineering Mansoura University, Egypt, E-mail: msmksasy@gmail.com

(2) MSc Student at Computers and Systems Engineering Department, Faculty of Engineering Mansoura University, Egypt, E-mail: a.maged.1988@gmail.com (3) Lecturer at Computers and Systems Engineering Department, Faculty of Engineering Mansoura University, Egypt, E-mail: amr.ali-eldin@mans.edu.eg (4) Prof. at Computers and Systems Engineering Department, Faculty of Engineering Mansoura University, Egypt, E-mail: Proffayez943@yahoo.com

\begin{tabular}{|c|}
\hline 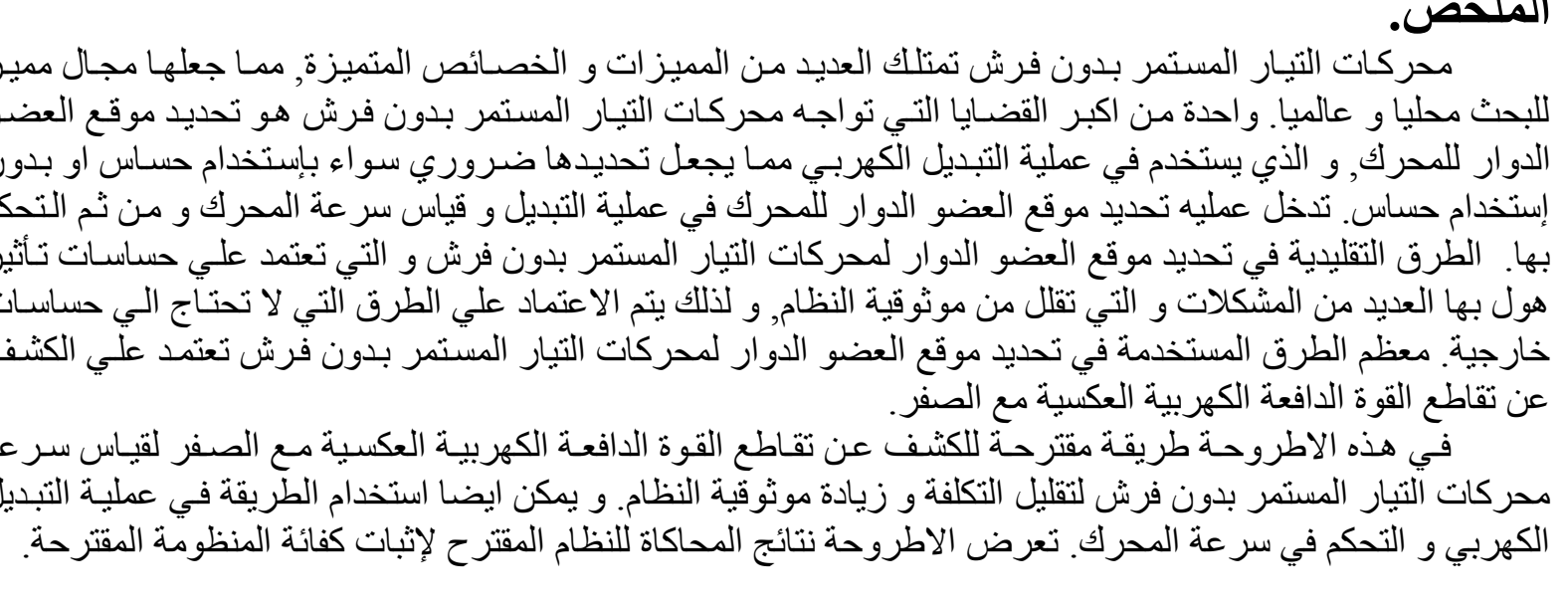 \\
\hline
\end{tabular}

\begin{abstract}
Sensorless Brushless DC (BLDC) motors have many advantages because of their greet characteristics which make them an interested field of research home and abroad. One of the biggest issues which face BLDC motors is the rotor position detection, as they are electrically commutated the rotor position must be detected with or without sensors. The position detection is used for commutation, speed measurement and speed control. The traditional method for BLDC motor rotor position detection which depends on Hall sensors has lots of problems that decrease the system reliability, so sensorless BLDC motor drives are extensively used. The sensorless position detection methods mostly use Zero Crossing Point (ZCP) detection techniques which depend on motor back EMF detection.

In this paper, a suggested method of ZCP detection for speed measurement is presented for BLDC motor, to decrease driver cost and increase system reliability, also the ZCP detection method can be for commutation and speed measurement. Simulation results are shown to prove system effectiveness.
\end{abstract}

\section{Keywords}

BLDC Motor, Sensorless, BLDC, ZCP, Wide speed range \& Speed Measurement. 


\section{Introduction}

Brushless Direct Current (BLDC) motors are one of the most interesting motor types and are very popularity. BLDC motors are used in lots of applications like medical equipment, home appliances, industrial automation, automotive, instrumentation equipment, and aerospace.

BLDC motors are electrically commutated and don't use brushed like normal DC motors. The eliminating of brushes give BLDC motors lots of advantages over brushed DC motors and induction motors [12] such as:

- High speed range and Better speed versus torque linearity.

- High efficiency and low power consumption.

- Long life and maintenance free.

- Low electrical noise and audio noise

- Higher delivered mechanical torque compared to the motor size.

BLDC motors are six steps electrically commutated, these six steps are $\mathrm{AB}, \mathrm{AC}, \mathrm{BC}, \mathrm{BA}, \mathrm{CA}$, and $\mathrm{CB}$ as the first phase is positive energized, the second phase is negative energized and the third phase is floating. For knowing the right commutation step and keep the rotor rotating continues, it is important to detect the rotor position. This position detection can be also used for measuring the motor speed, so cost can be decreased, and reliability can be increased.

In the traditional position detection method, Hall sensors are usually used, however, Hall Effect sensors are sensitive to temperature variations and magnetic field interruptions [10] which affect the sensor accuracy. Also, Hall sensors increase the motor size and require special installing. So, sensorless techniques are used to achieve simple and reliable method for controlling BLDC motors.

BLDC motor back EMF can be used for a detecting the rotor position without need to any external sensors as Hall sensors. While a BLDC motor rotates, each phase generates a voltage known as back
Electromotive Force or back EMF. Back EMF are proportional to main three parameters [12] which are; the magnet rotor magnetic flux, the angular velocity, and the number of conductor turns in the stator winding. The ZCPs of that back EMF can be used for detecting the rotor position [7- 8, 12].

In [3, 8 - 9] rotor position detection using ZCP detection has been discussed. The following issues are facing the ZCP detection.

- At start up, the back EMF is very small to be detected, and using open loop techniques at startup may cause start up failure.

- At standstill back EMF is equal to zero, and using the prepositioning techniques cause oscillations or start up failure.

- High common mode voltage that requires voltage dividers will decrease the sensitivity and hence increase the lower speed for closed loop control.

- Pulse Width Modulation (PWM) technique is used for controlling the motor speed which cause switching noise that is require filtering, which reduce the motor upper speed.

In [11] the back EMF is detected only during the PWM off period, where there is no common voltage or switching noise. But the detection during the off period gets harder as the PWM duty cycle or frequency increases.

Furthermore, the need to neutral point is solved using the free wheel diode method, but the detected back EMF in this method has low gain and contains third harmonics components.

The lines voltage differences method is used in [7 - 9]. Although the high gain it has (-2) for the back EMF detection [9], the voltage dividers usage eliminates this gain.

The speed torque linearity of BLDC motors and the capability of controlling the speed by changing the applied DC voltage are very important advantages, and hence come the importance of paying attention to the motor speed control. 
Motor speed control requires changing the electrical power delivered to the motor to achieve the required fixed speed with different applied torques, so speed control process contain two main parts; speed measurement, and speed adjusting. There are two main methods for controlling the speed, the Proportional Integral (PI) controller, and the fuzzy PI controller [13-15].

Using the derivative part in the proportional integral derivative controller increase the effect of noise, so the most industrial applications didn't use the derivative part, and use only PI controller to come over the noise issue and increase the system stability. And for this reason, in this paper the Proportional Integral (PI) controller will be used.

PI controller is very popular, but it is very hard to be tuned in case of none linearity [15] and most of these applications are nonlinear. Fuzzy PI controllers need good knowledge of the system.

In this paper, the issues and drawbacks of using the conventional method for ZCP detection are discussed in section 2. Fuzzy PI speed control is discussed in section 3. The suggested method for ZCP detection is proposed in section 4. Proposed ZCP detection method simulation results are discussed in section 5. Fuzzy PI controller simulation results are discussed in section 6. A comparison study is presented in section 7 .

\section{Conventional ZCP \\ Detection Drawbacks.}

Back EMF ZCP detection faces lots of problems which shall be solved to increase the measured speed accuracy and the system reliability. These problems mainly caused because of two reasons; Zero back EMF at standstill or very low at low speeds, and the using of voltage dividers and filters for signal conditioning. Using voltage dividers increase the lower value of motor speed for closed loop control, and using filters decrease the upper speed. So the motor speed is limited, and sensorless motor driver cost increased as the system gets more complicated.

In [11] a good solution for using voltage dividers and filters was presented, as the back EMF at the floating phase is detected directly during the PWM off period. The freewheeling diode method is used for detecting the phase voltage and the back EMF can be calculated using a simple equation.

For example the back EMF at phase $\mathrm{C}$ can be calculated as the following [11]:

$e_{c}=\frac{1}{3} e_{3}+\frac{2}{3} v_{c}$

Where $e_{c}$ is the back EMF at phase C, which is the floating phase, $\mathrm{V}_{\mathrm{c}}$ is the potential difference between phase $\mathrm{C}$ and the system ground, and $\mathrm{e}_{3}$ is the third harmonic voltage component.

The advantage of using the method presented in [11] is mainly eliminating both voltage dividers and filters. But the detected back EMF suffers from third harmonics and has low gain which makes this method for back EMF detection not very accurate and can't be used at startup or low motor speeds.

Another problem is that if the PWM duty cycle or frequency increases to increase the motor speed, back EMF detection during the off period gets harder, so in [11] the back EMF detection is done during the $\mathrm{ON}$ period in case of high speeds where the back EMF is larger and so the voltage dividers can be used. But the above method has some disadvantages as following:

- The diode forward voltage affects the detection of the ZCP especially in small back EMF values.

- Low back EMF gain, as the detection method has a gain of about 1.5 as noticed from equation 1 .

- There is still some switching noise which may affect the back EMF detection process at the beginning of the off period. 
- The detected back EMF contain third harmonics, but still can be used for ZCP detection [11], but the accuracy of the back EMF detection is suitable only for ZCP detection.

- The back EMF can be also measured by measuring voltage differences between the phases' lines [9], where the following equations can be used.

$V_{a b b c}=-2 e_{b n}$

$V_{c a a b}=-2 e_{a n}$

$V_{b c c a}=-2 e_{c n}$

Where $V_{a b b c}$ is the voltage difference between $\mathrm{V}_{\mathrm{bc}}$, and $\mathrm{V}_{\mathrm{ab}}$, and $\mathrm{V}_{\text {caab }}$ is the voltage difference between $\mathrm{V}_{\mathrm{ab}}$, and $\mathrm{V}_{\mathrm{ca}}$, and $V_{\text {bcca }}$ is the voltage difference between $\mathrm{V}_{\mathrm{ca}}$, and $\mathrm{V}_{\mathrm{bc}}$, and $\mathrm{e}_{\mathrm{bn}}$ is the back EMF of phase $B$, and $e_{a n}$ is the back EMF of phase $A$, and $e_{c n}$ is the back EMF of phase $C$. These equations can be used only for detecting the back EMF of floating phase. But the method in [9] has the following advantages:

- No need for the neutral point or any equivalent.

- High gain (-2)

- Not affected by the third harmonic components.

But voltage divider is used to reduce the high common mode voltage, and this voltage divider reduces the overall gain. Also, PWM, which is used for controlling the speed and cause switching noise which needs to be filtered. This filter reduces the upper motor speed limit as it cause a delay in the controller response.

\section{Fuzzy pi controller.}

Fuzzy PI controllers are logistic controllers which are based on fuzzy logic. Fuzzy controllers depend on rules which define the relation between inputs to get the outputs.

Fuzzy controllers' rules are a human readable rules like tall, medium height, short, so it is easier to be designed but it need a well knowledge about the system that needed to be controlled.
Fuzzy controllers depend on mapping the input to certain values called fuzzy sets. Also the output is mapped to convert the logistic results to analog output values. Any fuzzy controller consists of three parts (see Figure 1).

The first part is the Fuzzification part which is the process of converting the analogue input values to one of the fuzzy sets using a membership function.

The second part is the Rule Base which is the logistic rules defines the relation between inputs to get the output.

The final part is the Defuzzification part which is the process of converting the system output from its fuzzy set value to the related analogue output value.

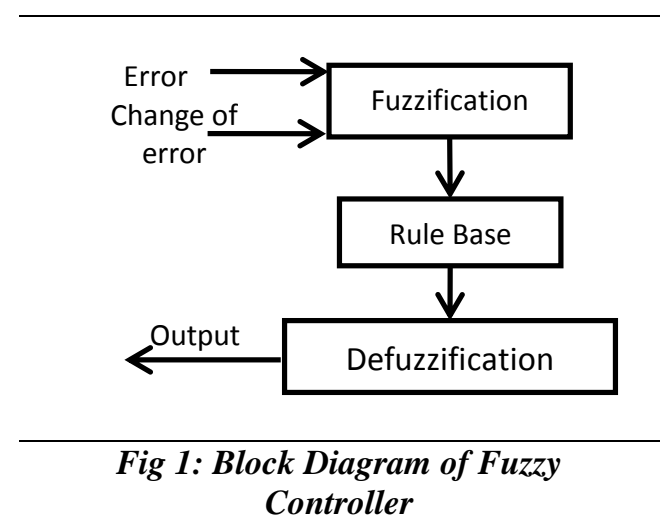

There are many membership functions but most fuzzy controllers use the rectangular membership function. The fuzzy sets must be more than two, the more fuzzy sets used the better performance and more stability achieved, but also more complexity of the system. For example of number of five fuzzy sets, the fuzzy sets may be called Negative Big NB, Negative N, Zero Z, Positive Bid PB, and Positive P.

\section{The proposed method for bldc motor zcp detection.}

The first step for detecting the back EMF using the lines voltage differences is to measure the phases voltages $\mathrm{V}_{\mathrm{a}}, \mathrm{V}_{\mathrm{b}}$, and $\mathrm{V}_{\mathrm{c}}$ using a sample and hold circuit. The problem is the time required by the coil to reach stability after switching off or on the 
supply voltage. To solve this problem the voltage shall be sampled at the end of the PWM off or on duration. Also the PWM frequency shall be chosen carefully, as if the PWM off or on duration is smaller than the phase coil response time, the switching noise will affect the detected back EMF and it will not be accurate. So there are three different positions for the phases' voltages sampling as in Figure 2.

The Suggested commutation control method has three sampling positions as following:

The first case is at starting the rotor motion from stand still; where the rotor speed is too small and the back EMF is small too so voltage dividers can't be used. In this case the position of the phases' voltages sampling is at the end of the PWM off duration. The PWM frequency at this case shall be small which enable using small duty cycle without failure at startup. The second case is at small speeds, small duty cycles. In this case the phases' voltages sample time is at the end of the PWM off duration. Also the PWM frequency shall be higher so the torque can be smoother.

The final case occurs at large speeds, large duty cycles. At this case the phases' voltages sample time is at the end of the PWM ON duration, and voltage dividers shall be used. Also the PWM frequency shall be high for reducing torque ripples.

After back EMF detection, the ZCP of the back EMF can be detected for both commutation and speed measurement. The motor shall be energized to the next step and the speed measurement sequence interrupted, if the sign of floating phase back EMF changed.

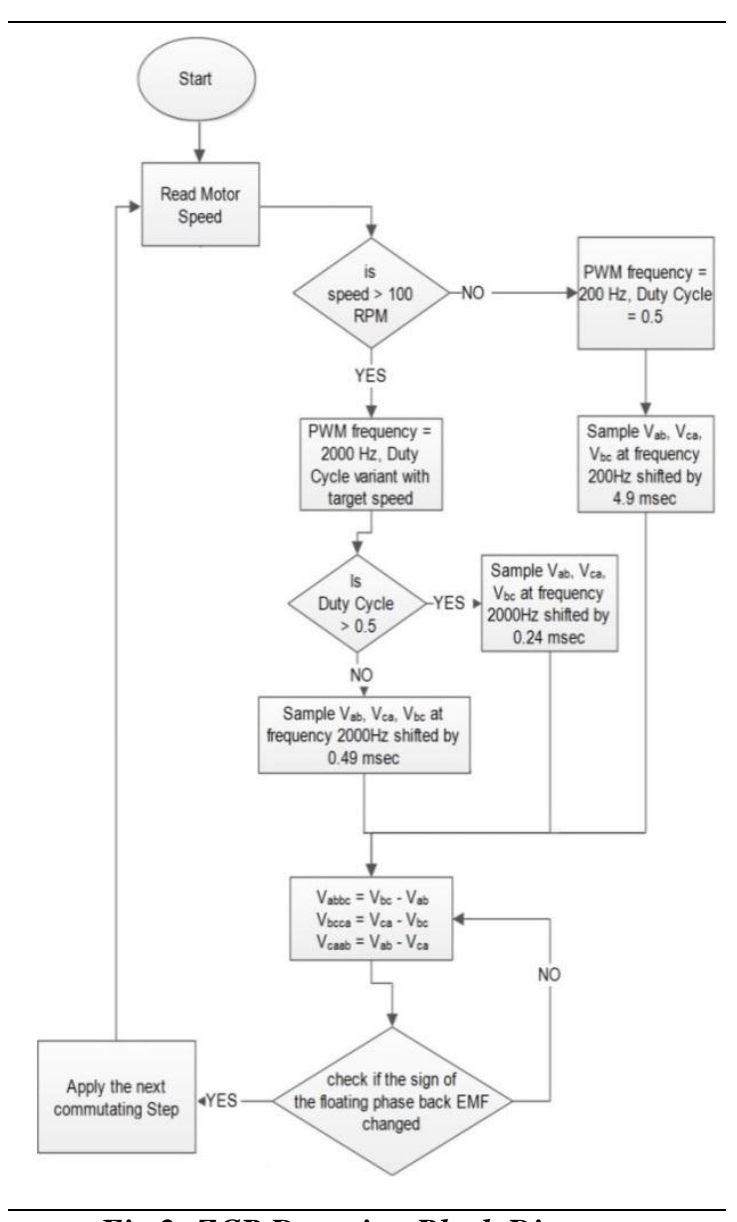

Fig 2: ZCP Detection Block Diagram

\section{Prposed zcp detection method simulation}

The Simulink Matlab is used for simulating the proposed method as shown in figure 3. The model can be divided into three parts; the BLDC motor with its driving bridge, the ZCP detection block which is used for commutation and also for speed measurement, and the initial position detector.

The first step for ZCP detection is line voltage difference detection. The line voltage $\mathrm{V}_{\mathrm{ab}}$ is shown in figure 4. It is clear that the PWM cause switching noise. This switching noise affects the ZCP detection process that is used for commutation and speed measurement 


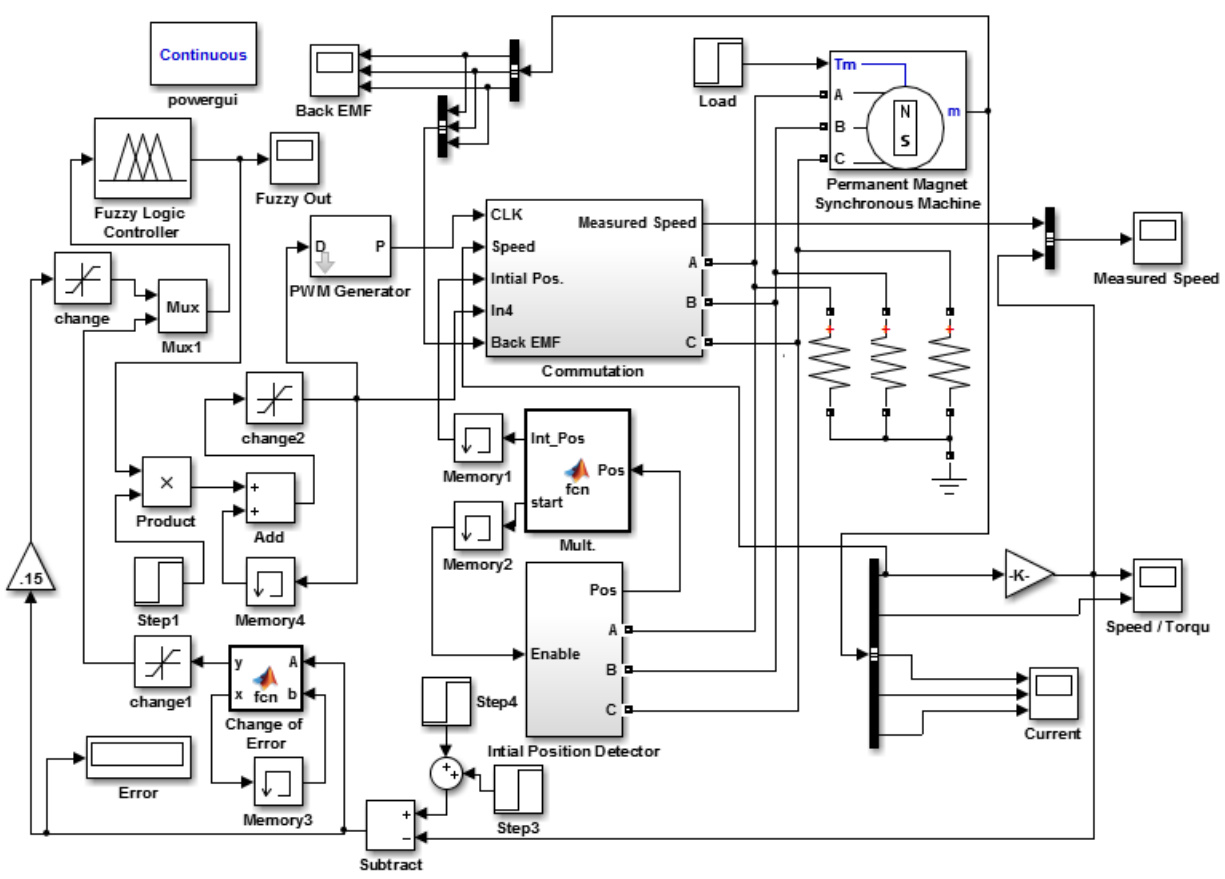

Fig 3: Simulink Model for Simulation.

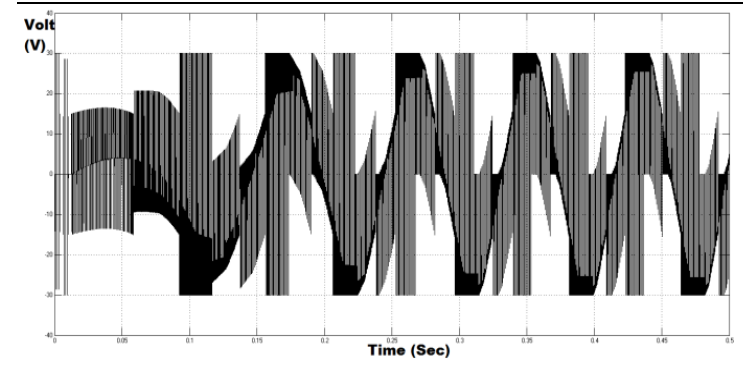

Fig 4: Line voltage.

As mentioned before the back EMF detection during PWM off or on period is used to eliminate the effect of this switching noise. Figure 5 shows the detected back EMF using the proposed method. It can be noticed that the proposed back EMF detection method has a large gain and is provides a large enough back EMF even at startup. Moreover, the detected back EMF has a very high signal to noise ratio and no third harmonics.

The detected back EMF has approximately amplitude of 4 volts at startup, which is very enough for the ZCP detection even at motor startup. The ripples are less than $1 \%$ from the back EMF value.

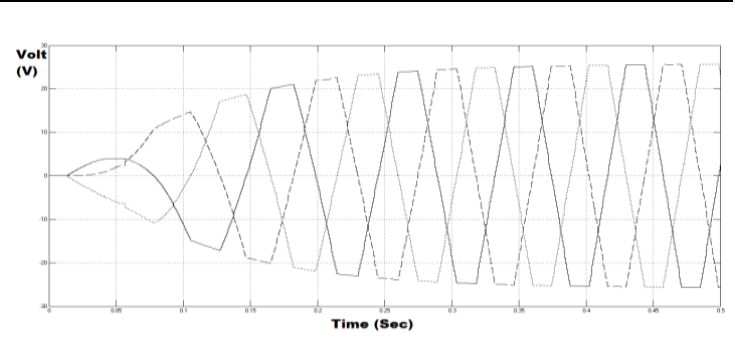

Fig 5: Detected back EMF.

After detecting the ZCP the speed of the motor can be detected. Each 6 ZCPs perform a complete electric cycle. Dependent on the number of the motor rotor poles, the mechanical rotations can be calculated from the following equation.

$\theta_{m}=\frac{2 \theta_{e}}{P}$

Where $\theta_{\mathrm{e}}$ is the electrical angle, $\mathrm{P}$ is the number of rotor permanent magnets poles, and $\theta_{\mathrm{m}}$ is the mechanical angle. The motor rotational speed $\omega_{m}$ can be calculated as following.

$\omega_{m}=\frac{d \theta_{m}}{d x}$

The speed curve of the BLDC motor is shown in figure 6 . The figure compare 
between the measured speed from the presented ZCP detection method and the actual motor speed at two speed levels, which are $700 \mathrm{rpm}$ and $900 \mathrm{rpm}$. It is clear that although the speed measuring process is not too fast but it is very accurate.

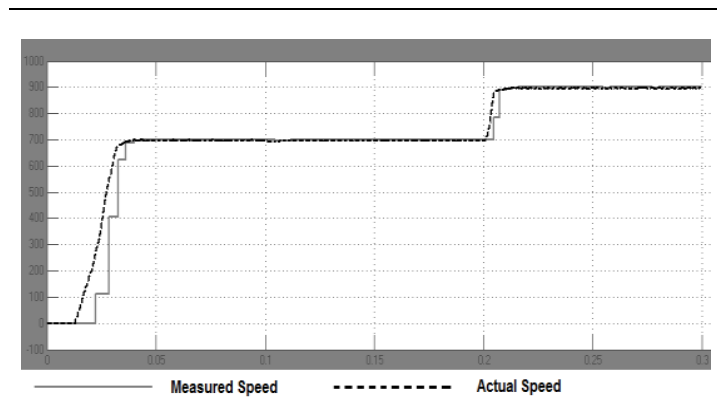

Fig 6: Speed Curve of the simulated BLDC motor.

\section{Fuzzy pi controller simulation.}

After the speed is measured, the motor speed shall be controlled. The proposed fuzzy PI controller uses 5 fuzzy sets, which are NB, N, Z, P, and PB. The first input to the fuzzy PI controller is the error $\mathrm{E}(\mathrm{N})$ where $\mathrm{N}$ is the sample number, which is defined by the difference between the measured speed $\omega_{P V}(N)$ and the targeted speed or the speed set point $\omega_{S P}(N)$ as shown in the following equation.

$$
\mathrm{E}(\mathrm{N})=\omega_{S P}(N)-\omega_{P V}(N)
$$

The detected ZCP can be used for measuring the current motor speed, as each six ZCPs means one electrical cycle. In the case of a BLDC motor with 2 poles permanent magnets rotor, one electrical cycle means one mechanical rotation. The motor speed can be calculated by measuring the rate of change of these rotations.

The second input to the fuzzy PI controller is the change of error which is the rate of error changing as shown in the following equations.

$$
\mathrm{CE}(\mathrm{N})=\mathrm{E}(N)-\mathrm{E}(N-1)
$$

Where $\mathrm{N}=1,2,3, \ldots$. And $\mathrm{CE}(\mathrm{N})$ is the change of error at sample $\mathrm{N}, \mathrm{E}(\mathrm{N})$ is the error at sample $\mathrm{N}, \mathrm{E}(\mathrm{N}-1)$ is the error at sample $\mathrm{N}-1$.

Table 1 shows the used fuzzy PI controller rule base, there are 5 fuzzy sets for the two inputs (error, and change of error), and 25 rule. The inputs to the fuzzy PI controller and the outputs from the fuzzy PI controller are converted to these sets using the membership function. The proposed fuzzy PI controller uses a triangular membership function as shown in figure 7.

Table 1 Used Rule Base for the Fuzzy PI Controller

\begin{tabular}{|l|l|l|l|l|l|}
\hline CE & NB & N & $Z$ & P & PB \\
\hline NB & NB & NB & NB & N & Z \\
\hline N & NB & NB & N & Z & P \\
\hline Z & NB & N & Z & P & PB \\
\hline P & N & Z & P & PB & PB \\
\hline PB & Z & P & PB & PB & PB \\
\hline
\end{tabular}

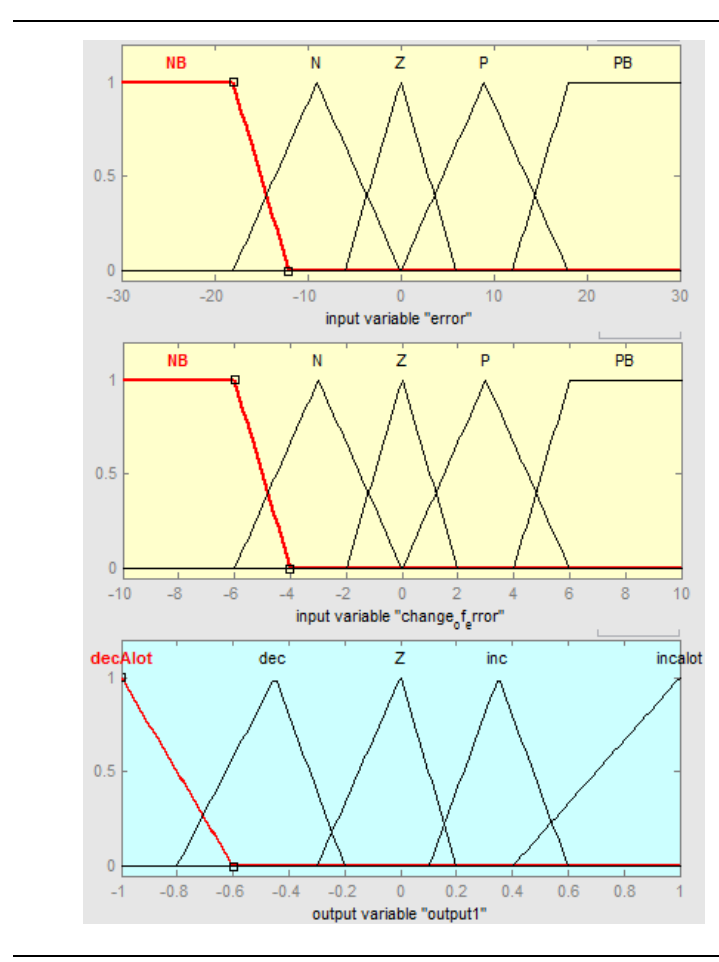

Fig 7: Fuzzy Membership Function

To tune the fuzzy PI speed controller and optimize its performance and make membership function range changes easier, the controller inputs, error, and change of error are multiplied by a factor. These two factors are $\mathrm{K}_{\mathrm{E}}$ for error and $\mathrm{K}_{\mathrm{CE}}$ for the 
change of error. Another gain $\mathrm{K}_{\text {out }}$ is multiplied by the output.

These factors are; for the error $\mathrm{K}_{\mathrm{E}}=$ 0.15 , for the change of error $\mathrm{K}_{\mathrm{CE}}=15$, and for the output $\mathrm{K}_{\text {out }}=0.003$.

For testing the Fuzzy PI controller, first the speed set point is set to 700 RPM, and at the time $\mathrm{t}=0.1 \mathrm{sec}$ a load of $0.1 \mathrm{NM}$ is added, finally at the time $t=0.2 \mathrm{sec}$ the set point of the speed increased to 900 RPM. The parameters of the used BLDC by simulation are shown in Appendix I. The speed response is shown in figure 8 , for the first step the rise time is about 0.02 sec, with approximately no overshoot, the settling time is about $0.023 \mathrm{sec}$.

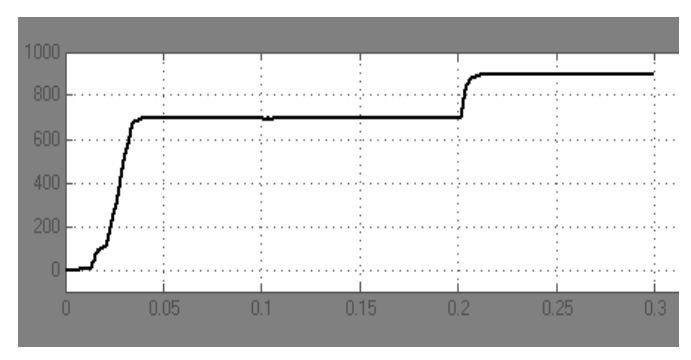

Fig 8: Speed Response using Fuzzy PI controller

The torque response is shown in figure 9. The start-up torque is about 2.1 N.M. After changing the set point at 0.2 sec to 900 RPM, the torque rise up to about 2.3 N.M, and then it has returned to the steady value.

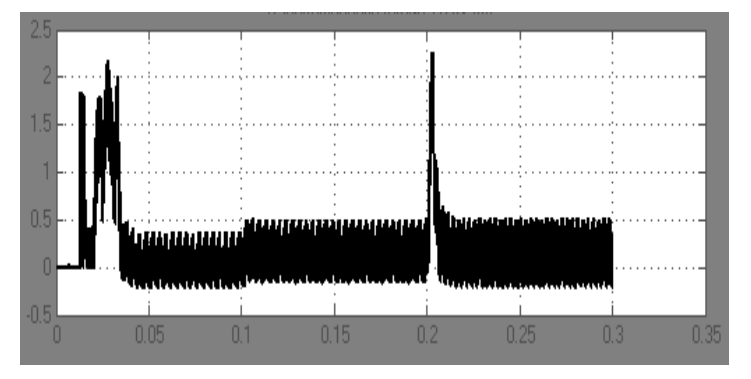

Fig 9: Torque response of the used Fuzzy PI Controller

The BLDC motor phases currents are shown in figure 10. The startup current is approximately $2 \mathrm{~A}$. At the set point changing to $900 \mathrm{RPM}$ at $0.2 \mathrm{sec}$ the current increase to reach about $2 \mathrm{~A}$, and then returned to the steady value.

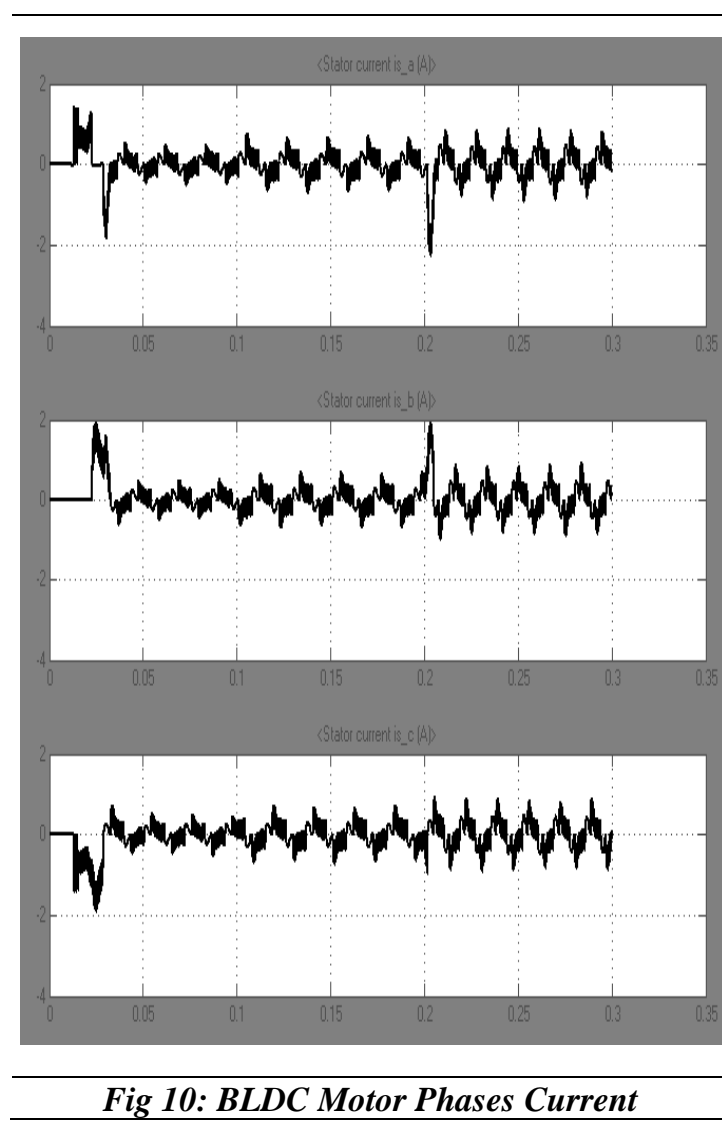

As shown in figure 11, the speed variations is less than $0.6 \%$, and when the $0.1 \mathrm{NM}$ load is added at $0.1 \mathrm{sec}$, the speed changed to 690 RPM and returned back to the steady value after about $0.01 \mathrm{sec}$.

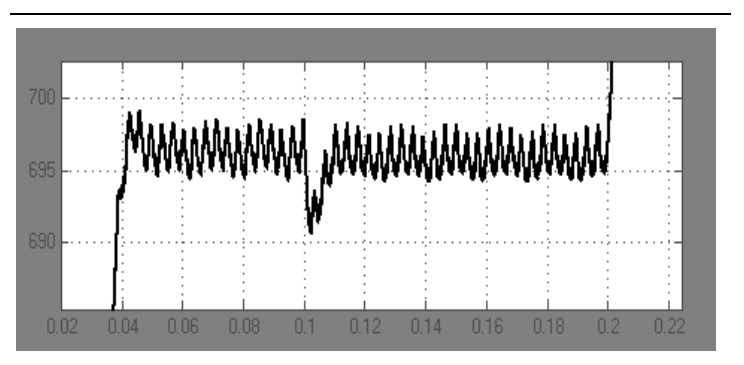

Fig 11: BLDC Motor Speed Variations

\section{Comparative and analytical study.}

In table 2 a comparison between the conventional BLDC motor ZCP detection methods and the proposed suggested method is presented. 
Table 2 comparison between Conventional ZCP Detection Method and the Proposed One.

\begin{tabular}{|c|c|c|c|}
\hline Ref & & $\begin{array}{c}\text { Reference } \\
\text { solutions }\end{array}$ & $\begin{array}{c}\text { Suggested } \\
\text { solutions }\end{array}$ \\
\hline \multirow[b]{2}{*}{$\begin{array}{l}3 \\
, 7 \\
, 9\end{array}$} & $\begin{array}{c}\text { Applied } \\
\text { solutions }\end{array}$ & \begin{tabular}{|lr}
-has a gain of -2 \\
but the voltage \\
dividers reduced \\
the sensitivity. \\
-using r filters \\
reduce \\
speed.
\end{tabular} & $\begin{array}{l}\text { - Allow larger speed } \\
\text { range. } \\
\text {-No voltage dividers } \\
\text { are used. } \\
\text {-No filter is used. }\end{array}$ \\
\hline & Results & $\begin{array}{l}\text { Time before } \\
\text { starting } \\
\text { acceleration: } \\
800 \mathrm{~ms} \\
\text { Value of back } \\
\text { EMF while } \\
\text { startup: <0.3 V } \\
\text { Back EMF } \\
\text { ripples: <35 \% } \\
\text { Unwanted } \\
\text { Reversed } \\
\text { direction: } \text { Yes } \\
\end{array}$ & $\begin{array}{l}\text { Time before starting } \\
\text { acceleration: }<30 \mathrm{~ms} \\
\text { Value back EMF } \\
\text { while startup: }<4 \mathrm{~V} \\
\text { Back EMF ripples: } \\
<1 \% \\
\text { Unwanted Reversed } \\
\text { direction: No }\end{array}$ \\
\hline \multirow[t]{2}{*}{10} & $\begin{array}{l}\text { Applied } \\
\text { solutions }\end{array}$ & $\begin{array}{l}\text {-Needs Complex } \\
\text { Calculations. } \\
\text {-Need very fast } \\
\text { back } \quad \text { EM } \\
\text { detection system } \\
\text {-system } \\
\text { complexity } \\
\text { increase while the } \\
\text { motor speed } \\
\text { increase. } \\
\end{array}$ & $\begin{array}{l}\text {-No Complex } \\
\text { Calculations. } \\
\text {-doesn't need that } \\
\text { fast system. } \\
\text {-Can be used for } \\
\text { wide speed range. }\end{array}$ \\
\hline & Results & $\begin{array}{l}\text { Speed ripples: } \\
<1.7 \% \\
\text { Unwanted } \\
\text { Reversed } \\
\text { direction: No }\end{array}$ & $\begin{array}{l}\text { Speed ripples: < } \\
1.5 \% \\
\text { Unwanted Reversed } \\
\text { direction: No }\end{array}$ \\
\hline \multirow[t]{2}{*}{11} & $\begin{array}{c}\text { Applied } \\
\text { solutions }\end{array}$ & $\begin{array}{l}\text {-Detected Back } \\
\text { EMF contains } \\
\text { third Harmonics } \\
\text {-Small back EMF } \\
\text { gain. }\end{array}$ & $\begin{array}{l}\text {-detected back EMF } \\
\text { doesn't contain third } \\
\text { Harmonics. } \\
\text {-High gain } \quad(-2)\end{array}$ \\
\hline & Results & \begin{tabular}{|l|} 
Unwanted \\
Reversed \\
direction: Yes
\end{tabular} & $\begin{array}{l}\text { Unwanted Reversed } \\
\text { direction: No }\end{array}$ \\
\hline
\end{tabular}

In [13] a fuzzy PI speed controller and a PI speed controller are used to control a BLDC motor speed. The used motor parameters in [13] are the same used in this paper as shown in Appendix I. Table 3 shows a comparison between the performance of the Fuzzy PI controller in [13] and the proposed on in this paper.

In [13] for the Fuzzy PI controller, the settling time is $0.05972 \mathrm{sec}$. The other performance parameters were extracted from the reference speed curve. In the first step where the speed changed from 0 to 700 RPM, the proposed fuzzy PI
Controller performance is better and has a very small rise time about $0.02 \mathrm{sec}$, and small settling time about $0.023 \mathrm{sec}$ with very small overshoot.

For the second step where the speed changes from 700 to 900 RPM, the performance of the proposed fuzzy PI controller is almost as the rise time is about $0.004 \mathrm{sec}$, and settling time is about 0.005 sec.

In the proposed fuzzy PI controller the start-up torque in the first step is about 2.2 N.M, while in [13] the start-up torque is about 0.9781 N.M. In the proposed fuzzy PI controller the start-up current is about 2A, while in [13] the start-up current is about $1 \mathrm{~A}$.

Table 3 comparison between Conventional Speed Controller and the Proposed One.

\begin{tabular}{|c|c|c|c|}
\hline $\begin{array}{l}\text { Settling } \\
\text { time } \mathrm{T}_{\mathrm{s}}\end{array}$ & $\begin{array}{c}\text { Rise time } \\
\mathrm{T}_{\mathrm{r}}\end{array}$ & $\begin{array}{c}\text { Speed } \\
\text { step }\end{array}$ & \\
\hline $\begin{array}{l}0.05972 \\
\text { sec }\end{array}$ & $0.039 \mathrm{sec}$ & $0-700$ & \multirow{2}{*}{$\begin{array}{l}\text { Reference } \\
{[13]} \\
\text { Fuzzy PI } \\
\text { Controller }\end{array}$} \\
\hline $\begin{array}{l}0.018 \\
\text { sec }\end{array}$ & $0.01 \mathrm{sec}$ & $700-900$ & \\
\hline $\begin{array}{l}0.023 \\
\text { sec }\end{array}$ & $0.02 \mathrm{sec}$ & $0-700$ & \multirow{2}{*}{$\begin{array}{l}\text { Proposed } \\
\text { Fuzzy PI } \\
\text { Controller }\end{array}$} \\
\hline $\begin{array}{l}0.005 \\
\text { sec }\end{array}$ & $0.004 \mathrm{sec}$ & $700-900$ & \\
\hline
\end{tabular}

\section{Conclusion and future work.}

A suggested control method for BLDC motor speed measurement using ZCP detection without any external sensors is proposed in this paper. This method based on the lines voltage differences during the PWM off period for back EMF measuring. The simulation results were presented to prove that the presented back EMF measuring technique is sensitive and proved accurate ZCP detection.

A BLDC motor Fuzzy PI speed controller is presented in this paper using measured speed from the proposed ZCP detection method. A comparative study has been done between the used references and 
the presented Fuzzy PI controller to evaluate the presented speed controller performance, and it proved that in general the presented speed controllers have better performance.

A future work could be done to enhance the motor torque characteristics and reduce the motor current ripples by adding current control function to the proposed speed controller.

\section{Appendix i}

The Parameters of the used BLDC Motor for simulation.

\begin{tabular}{|l|c|}
\hline Rated speed & 3000 RPM \\
\hline Number of Poles & 4 \\
\hline Resistance/Phase (ohm) & $10.91 \mathrm{ohm}$ \\
\hline Inductance/Phase(H) & $30.01 \mathrm{e}-3 \mathrm{H}$ \\
\hline $\begin{array}{l}\text { Moment of } \\
\text { inertia(kg/m2) }\end{array}$ & $2 . \mathrm{ge}-4 \mathrm{~kg} / \mathrm{m} 2$ \\
\hline $\begin{array}{l}\text { Voltage } \\
\text { constant(V_peak L-L / } \\
\text { krpm) }\end{array}$ & 136.1357 \\
\hline \begin{tabular}{l} 
Torque constant(Nm/A) \\
\hline
\end{tabular} & 1.3 \\
\hline
\end{tabular}

\section{References}

[1] C. L. Baratieri, H. Pinheiro "A Novel Starting Method for Sensorless Brushless DC Motors with Current Limitation" presented at Electrical Machines (ICEM) 2012 International Conference on, 2-5 Sept. 2012.

[2] Kai-Sheng Kan, Ying-Yu Tzou " Adaptive Soft Starting Method with Current Limit Strategy for Sensorless BLDC Motors" presented at Industrial Electronics (ISIE) 2012 IEEE International Symposium on, 28-31 May 2012.

[3] Yu-Jhen Fu, Lu-Ting Huang, RueyYue Lin, and Cheng-Hu Chen "Reliable Starting Method for Sensorless Brushless DC Motor Drive" presented at Advanced Intelligent Mechatronics (AIM) 2012 IEEE/ASME International Conference on, 11-14 July 2012.
[4] Ming Lu, Yaohua Li "A Novel Sensorless Starting Method of BLDC Motor for Large Inertia Systems" presented at Electronic and Mechanical Engineering and Information Technology (EMEIT) 2011 International Conference on, 12-14 Aug. 2011.

[5] Qiang Wu, Guangwei Meng, Hao Xiong, Huaishu Li, Libing Zhou " A Novel Starting Control for Sensorless Three-Phase Permanent-Magnet Brushless DC Motor" presented at Electric Information and Control Engineering (ICEICE) 2011 International Conference on, 15-17 April 2011.

[6] Wang Zhongwei, Liu Haiting, Zhao Xueping " Simulation Analysis of BLDC Motor Three Step Starting" presented at Control, Automation and Systems Engineering (CASE) 2011 International Conference on, 30-31 July 2011.

[7] Li Chunfeng, Yu Weibo, Tang Wusheng "Study on Rotor Position of Sensorless Brushless DC Motors Through Back Electromotive Force Detection" presented at E-Product EService and E-Entertainment (ICEEE) $2010 \quad$ International Conference on, 7-9 Nov. 2010.

[8] Xiong hui,Xue YanBo " The Design of of Brushless DC Motor BackEMF control" presented at Environmental Science and Information Application Technology (ESIAT) $2010 \quad$ International Conference on, 17-18 July 2010.

[9] P. Damodharan, R. Sandeep and K. Vasudevan "Simple position sensorless starting method for brushless DC motor" IET Electr. Power Appl., 2008, 2, (1), pp. 49-55.

[10] Yen-Chuan Chang and Ying-Yu Tzou "A New Sensorless Starting Method for Brushless DC Motors without Reversing Rotation" presented at Power Electronics 
Specialists Conference, 17-21 June 2007. PESC 2007. IEEE.

[11] Jianwen Shao "Direct Back EMF Detection Method for Sensorless Brushless DC (BLDC) Motor Drives" M.S. thesis, Dept. Electron. Eng., Virginia Polytechnic Institute and the State University September, 2003.

[12] Padmaraja Yedamale "Brushless DC (BLDC) Motor Fundamentals" Microchip Technology Inc, AN885 application note, 11/11/2003. Available:

http://ww1.microchip.com/download s/en/AppNotes/00885a.pdf

[13] Madhusudan Singh , Archna Garg "Performance Evaluation of BLDC Motor with Conventional PI and Fuzzy Speed Controller " presented at $\quad 10.1109 /$ IICPE.2012.6450516

Conference: Power Electronics (IICPE), 2012 IEEE 5th India International Conference on.

[14] Sreekala.P , and Prof.Dr.A.Sivasubramanian "Speed Control Of Brushless Dc Motor With Pi And Fuzzy Logic Controller Using Resonantpole Inverter" presented at Innovative Smart Grid Technologies - India (ISGT India), 2011 IEEE PES, 1-3 Dec. 2011

[15] R. Arulmozhiyal, and R.Kandiban "An Intelligent Speed Controller for Brushless DC Motor" presented at Industrial Electronics and Applications (ICIEA), 2012 7th IEEE Conference on, 18-20 July 2012 . 